\title{
Review
}

CARDIOLOGY

\section{Clues to the Pathophysiology of Sudden Cardiac Death in Obstructive Sleep Apnea}

\author{
Tatyana Olegovna Brodovskaya Irina Fedorovna Grishina \\ Tatiana Fedorovna Peretolchina Olga Georgievna Solenskaia \\ Olga Petrovna Kovtun Olga Vyacheslavovna Teplyakova \\ Sergey Aleksandrovich Chernjadev Artem Anatolievich Popov \\ Viacheslav Valentinovich Kurmin
}

Federal State Budgetary Educational Institution of Higher Education "Ural State Medical University,"

Ministry of Healthcare of the Russian Federation, Yekaterinburg, Russia

\section{Keywords}

Obstructive sleep apnea · Sudden cardiac death .

Pathophysiology

\begin{abstract}
Background: Risk assessment of sudden cardiac death (SCD) is multifactorial and complex, especially among individuals without established cardiovascular disease. There are insufficiently investigated conditions that can affect arrhythmogenesis. One such condition is obstructive sleep apnea (OSA) syndrome, which is not on the list of risk factors of the Russian National Society of Arrhythmology. Objective: The aim of this review article is to discuss clues to the pathophysiology of SCD in OSA subjects. Methods: We searched the literature for data reporting the impact of apnea on arrhythmogenesis. The preferred languages were English and Russian. The most important clinical reports, as well as biochemistry and pathophysiology guides, were selected for inclusion in the review. Results: It was clearly observed in the
\end{abstract}

searched literature that OSA is the crucial aspect of arrhythmogenesis. Among the clues are intermittent nocturnal hypoxia, reactive oxygen species, cardiomyocyte metabolism disturbances, myocardial electric heterogeneity, and intrathoracic pressure changes. Conclusion: This review emphasizes the importance of the inclusion of OSA in the list of risk factors of the Russian National Society of Arrhythmology.

(c) 2018 The Author(s)
Published by S. Karger AG, Basel

\section{Introduction}

According to modern definitions, sudden death is a nontraumatic, unexpected fatal event occurring within $1 \mathrm{~h}$ of the onset of symptoms in an apparently healthy subject. The European Society of Cardiology (ESC), with the endorsement of the Association for European Pediatric and Congenital Cardiology, has outlined the conditions of "sudden cardiac death" (SCD): (1) a congenital or acquired potentially fatal cardiac condition was known to

\section{KARGER}

E-Mail karger@karger.com www.karger.com/crd (c) 2018 The Author(s)

Published by S. Karger AG, Basel

Karge

Open access

This article is licensed under the Creative Commons AttributionNonCommercial-NoDerivatives 4.0 International License (CC BYNC-ND) (http://www.karger.com/Services/OpenAccessLicense). Usage and distribution for commercial purposes as well as any distribution of modified material requires written permission.
Tatyana Olegovna Brodovskaya

Federal State Budgetary Educational Institution of Higher Education

"Ural State Medical University," Ministry of Healthcare of the Russian Federation

RU-Yekaterinburg (Russia)

E-Mail tbrod80@gmail.com 
be present; (2) autopsy identified a cardiac or vascular anomaly as the probable cause of the event; or (3) no obvious extracardiac causes were identified by postmortem examination, so an arrhythmic event was the likely cause of death [1]. Despite certain success in prevention and treatment, annually, cardiovascular pathology takes about 17 million lives worldwide, $25 \%$ of which fit the definition of SCD [1-4]. Risk assessment of SCD is multifactorial and complex, especially among individuals without established cardiovascular disease [5]. Conducted research studies suggest that, in addition to the established SCD risk factors, there are also insufficiently investigated conditions that can affect structural and functional heart changes and arrhythmogenesis [5-7]. One such factor may be obstructive sleep apnea (OSA) syndrome $[1,8]$.

\section{OSA and Cardiovascular Disease}

The ESC, in its guidelines on SCD prevention (2015) [1], devoted 1 section to OSA influence. Meanwhile, the All-Russian Scientific Society of Clinical Electrophysiology, Arrhythmology and Pacemakers does not currently include OSA in the list of SCD risk factors [9]. It is impossible to overestimate the importance of 18 years of cohort surveillance of OSA patients in Wisconsin, USA, which demonstrated a 3.8-fold increase in total mortality and cardiovascular mortality 5.2 times more likely than in those observed without sleep respiratory disturbances [10]. This pattern was confirmed by the results of an observational study of residents of the West Australian settlement of Busselton, which estimated the risk of an increase in overall mortality among subjects with average and severe sleep apnea to be 4.2 times, and a $50 \%$ increase among subjects with light OSA [11]. In a prospective study, Gami et al. [12] included 10,701 adults with a mean follow-up period of 15 years, and they found that the severity of nocturnal hypoxia is a significant risk factor for SCD. The exclusion of already studied risk factors from the analysis, e.g., coronary artery disease, arterial hypertension, heart failure, and cardiomyopathy, determined that the degree of oxygen saturation is an independent SCD indicator. The oxygen saturation threshold was determined to be $<93 \%$, at which point the risk of SCD increases 2.9 -fold. It is important to note that, in addition to the apnea/hypopnea index (AHI) (an established cardiovascular risk factor), the average oxygen saturation and nadir saturation during sleep played an important role in SCD risk. The effect of the latter was somewhat lower than the average oxygen saturation, but higher than that of AHI, with an odds ratio of 1.6, while the effect of minimum saturation $(<78 \%)$ was 2.6 .

OSA severity, according to the practical guidelines of the American Academy of Sleep Medicine, depends on AHI, i.e., the number of episodes of breath stops per hour. The degree of OSA is considered to be mild at AHI $5-15 / \mathrm{h}$, moderate at AHI $15-30$, and severe at AHI $>30$ [13]. The prevalence of OSA in the general cohort of the population is $3-7 \%$ in males and $2-5 \%$ in females $[14,15]$. As well as gender, there is an association with age [16]. A growing amount of evidence confirms the pronounced relationship between OSA and cardiovascular diseases, including atherosclerosis, coronary heart disease, arterial hypertension, and heart failure $[17,18]$ as well as SCD [19]. Here, we discuss the underlying pathophysiological mechanisms of SCD, such as intermittent nocturnal hypoxia, autonomic function, ion-channel remodeling, electrolyte shifts, and others.

\section{Pathophysiological Mechanisms of SCD}

\section{Intermittent Nocturnal Hypoxia}

Respiratory events, namely, the cessation of pulmonary ventilation due to upper respiratory tract collapse, are accompanied by episodes of hypoxia. During episodes of apnea, prerequisites arise for the accumulation of excesses of carbonic acid and hypercapnic hypoxia. The result is a strain on biochemical and physiological mechanisms [20, 21]: buffer systems, redistribution of electrolytes in intracellular and extracellular fluids, changes in hemodynamics, and pulmonary ventilation [20]. Excess carbon dioxide in the form of carbonic acid dissociates into anion and proton hydrogen. The shear stress of the latter activates the body's buffer systems, including hydrocarbonate buffer, whose stock is mainly represented by the potassium and sodium salts of carbonic acid. The transmembrane current of hydrogen protons occurs in exchange for potassium ions, which are one of the most important cardiomyocyte action potential components. Since phase 3 of the action potential of myocardial cells is mainly provided by the current of potassium ions, its reduction within cardiomyocytes leads to an extension of repolarization, and the conditions for the appearance of early postdepolarization trigger activity.

Simultaneously, as a result of an internal cardiomyocyte membrane charge decrease, the magnitude of the excitation threshold changes and the conditions for premature potentials of action and late postdepolarization are 
created. Such mechanisms can contribute to life-threatening ventricular arrhythmias and SCD. One such proof of balance changes in intracellular potassium ions was demonstrated by the research of Jiang et al. [22], which suggested the mechanistic links between OSA and the extension of repolarization elongation. Examining matrix RNA OSA patients, the authors established a decrease in the expression of the KCNQ1, KCNH2, KCNE1, KCNJ2, and KCNA5 potassium-channel genes, which were inversely related to AHI. The expression of KCNQ1, $K C N H 2$, and $K C N E 1$ was determined by the severity of hypoxia. After 4 weeks of OSA treatment with CPAP therapy, positive dynamics of KCNQ1 and KCNJ2 expression were established. Unfortunately, in this particular study, the QT interval characteristics reflecting the processes of myocardial repolarization were not evaluated. Meanwhile, detection of electrical myocardium instability markers can provide evidence of such a relationship.

\section{Electrical Myocardial Instability}

Russian national guidelines for the Holter monitoring methodology in clinical practice have been used to determine ECG criteria for electrical myocardial instability, which include QT interval prolongation, T-wave microalternation, and late ventricular potentials [23]. These criteria relate to the risk factors of SCD, and the ESC [1] and All-Russian Scientific Society of Clinical Electrophysiology, Arrhythmology and Pacemakers recommend they be determined [9]. In general, the effect of hypoxia on myocardial repolarization remains poorly understood. However, the data in the literature suggest that such relationships are possible. The repolarization disorders that manifest the QT interval elongation were presented by Latshang et al. [24], who established reliable relationships between hypoxia and the magnitude of the corrected QT interval. Interestingly, during the day, in the absence of episodes of hypoxia, OSA patients had an increased SCD risk against the background of a prolonged QT interval, which, according to Shamsuzzaman et al. [25], may reflect the voltage of the compensatory capabilities of buffer electrolyte systems. Kilicaslan et al. [26], on the other hand, did not observe a significant QT prolongation, but revealed an increase in Tp-e interval, Tp-e/ QT ratio, and Tp-e/QTc ratio among OSA patients. The results of a study by Borodin and Lyshova [27], in their attempt to estimate the daily dynamics of the QT interval, are of interest. The authors found a significant difference between the repolarization rates of healthy individuals and patients with OSA, both during sleep and wakefulness. It is important that, even at daytime, there was a

Clues to the Pathophysiology of SCD in OSA correlation between the duration of the QT interval and the AHI, although there was a tendency for the connections to weaken during the waking period.

An analysis of the dynamics of the QT interval before and after the treatment of OSA by continuous positive airway pressure (CPAP) is given in a study by Rossi et al. [28]. This study characterized the trend towards a significant QT interval elongation among patients who discontinued therapy. Patients compliant with this type of treatment had lower duration and variance of the QT interval. The results of experimental studies are of great interest. Eleven healthy volunteers suffered acute hypoxia via the method of normobaric hypoxia with inhalation of an air mixture with a reduced oxygen content (i.e., an $\mathrm{O}_{2}$ concentration of $11 \%$ ) for $15 \mathrm{~min}$ [29]. The authors recorded an increase in the absolute values of QT as well as an increase in the corrected QT interval during hypoxia and noted the normalization of the repolarization indices after stopping the supply of the oxygen-depleted air mixture. The influence of the degree of hypoxia on the changes in repolarization was established by Baumert et al. [30], proving both the direct relationship between the AHI and the QT interval duration, and the inverse correlation between the repolarization duration and nadir oxygen saturation. Such influences allow us to consider the changes in repolarization in the context of the pathogenetic connection with hypoxia and suggest an increased risk of developing life-threatening arrhythmias.

Another fact that confirms the predisposition of OSA patients to arrhythmia development is the result of the investigation by Chan and Antonio [19], which established an increase in the T-wave alternation in OSA. The tendency to an increased T-wave alternation with an increase of heart rate was established by a meta-analysis of Nemati et al. [31]. The authors suggested that autonomous regulation significantly contributed to the electrical remodeling of the myocardium. Structural changes in the myocardium can be the reason for the re-entry of the excitation wave. However, there were no significant differences in an evaluation of signal-averaged ECG in patients with OSA. Sanner et al. [32] revealed late ventricular potentials in $7.8 \%$ of cases, but the differences were not reliable in comparison with those examined without respiratory disturbances in sleep. Four years later, the same team of authors, having accumulated numerous observations, found a proportional increase in late ventricular potentials along with an increase in AHI. The average follow-up period was 26.7 months. During this time, syncope was diagnosed in 2 patients and 1 case of SCD was recorded [33]. 


\section{Metabolism of Cardiomyocytes}

The available evidence of the electrical instability of the myocardium in OSA patients suggests the existence of pathophysiological mechanisms underlying the arrhythmogenesis in patients with hypoxia. The considered homeostatic shifts, i.e., gene expression change, change in voltage of the buffer systems, and electrolyte shifts, could be at the base of the decrease in repolarization reserve and constitute one of the keys to understanding the mechanisms of arrhythmogenic cardiac remodeling on a background of intermittent hypoxia [2]. At the heart of the high myocardial sensitivity to oxygen deficiency are the features of cardiomyocyte metabolism. As known, most of the energy requirement is provided by the metabolism of fatty acids, and the rest by the utilization of glucose [21]. Hypoxia, being the hypoenergetic state for cardiomycyte metabolism, is accompanied by a reduction in the synthesis of ATP, and therefore has negative inotropic, butmotropic, dromotropic, and chronotropic effects. In cardiomyocyte hypoxia, intracellular accumulation of pyruvic acid occurs, with the restoration of pyruvate to lactate; therefore, the acid-base balance of the cytosol is shifted to the acidic side, and the enzyme activity decreases.

\section{Reactive Oxygen Species}

Pro-oxidants make a significant contribution [34] by generating reactive oxygen species (ROS), represented by oxygen radicals and nonradical oxygen derivatives. Without going into the list of ROS, we noted their damaging effect on cell membranes, enzyme inactivation, lipid oxidation, and DNA. The long half-life of some ROS, e.g., superoxide radicals, allows them to penetrate the cytoplasmic reticulum and damage the main energy stations of the cell mitochondria. The resultant effect is damage to the cardiomyocyte ultrastructure, inflammation, necrobiosis, and myocardial degeneration [20]. These, together with electrolyte shifts and change in voltage of the transmembrane transport, appear to underlie the arrhythmogenic remodeling of the myocardium. Thus, conditions are being potentiated to reduce the reserve of repolarization, the electrical myocardial heterogeneity, and the reentry of the excitation wave.

\section{Autonomic Regulation}

Upper respiratory tract collapse, leading to a decrease in partial oxygen pressure, activates chemo- and baroreflexes, the sympathetic nervous system, and catecholamine release. The result is elevated blood pressure, heart overload, artery spasm in the lungs, kidneys, and liver, and the centralization of blood flow. In 1984, Guil- leminault et al. [35] described the relationship between the longest episodes of apnea and the irregularity of RR intervals, calling their observations "cyclic variability of the heart rate." The authors proposed using the alternation of RR interval as a basis for screening OSA, but their observations were not widely used in practice. Similarly, Le Heuzey et al. [36] observed the visual extension of the RR interval and a significantly greater difference between minimum and maximum heart rate overnight in OSA patients. However, these observations were not quantified in accordance with the criteria of classic time analysis. At the same time, both studies suggested using the duration of the RR interval as a tool for preliminary OSA identification.

At present, the assessment of heart rate variability has become a routine stage of ECG long-term monitoring systems. Spectral analysis of heart rate variability was described by Shiomi et al. [37], who used the latter to evaluate the advantages of mandibular devices in OSA treatment, which reduced the power of very low frequencies without other spectral changes. Such observations allow us to assume that hypoxia initiates short-term activation of the sympathetic nervous system, in contrast to healthy individuals, in whom the change in the spectrum of the heart rhythm at night is mainly mediated by parasympathetic modulations. As evidence for such arguments, the results of several studies $[38,39]$ have established that there is a tendency to increase sympathetic modulations and reduce parasympathetic influence on heart rhythm during sleep in patients with OSA. Montemurro et al. [40] observed that OSA patients who did not complain of daytime drowsiness had higher ultralow frequency modulations than patients who had problems with excessive daytime sleepiness. This fact made possible the assumption of an increased sympathetic nervous system tone in this category of patients. Similar evidence of increased sympathetic activity was previously presented by Somers et al. [41] in a cohort of patients with OSA, in whom heart rate variability assessment was performed in the daytime, during wakefulness, under normoxia conditions. Narkiewicz et al. [42] indicated an increase in heart rate at daytime in OSA patients, which may indicate strain on the sympathetic nervous system. Variations in heart rate variability against the background of OSA treatment are of interest. Therefore, it was established [43] that the use of CPAP therapy already on the first night improves autonomic regulation of the heart rhythm, and that inhalation of oxygen by patients with OSA significantly decreases the contribution of sympathetic modulations, blood pressure, and heart rate [44]. 


\section{Rhythm and Conduction Disorders}

The result of increased sympathetic nervous system tone may be triggered by myocardium activity, which, under conditions of a reduced reserve of repolarization, can lead to the onset of fatal arrhythmias. According to the literature, there is evidence of an increase in the frequency of rhythm disturbances and conduction against a background of intermittent hypoxia. The most frequent rhythm disturbances in OSA are ventricular tachycardia, frequent ventricular extrasystole, atrioventricular blockade of the second degree, and sinus arrest [45-49], which are described in $30-50 \%$ of patients with OSA. Concerning the structure of rhythm disturbances, $18-30 \%$ are seen in sinus bradycardia, about $5-11 \%$ in sinus arrest, $5-39 \%$ in atrial fibrillation, $19-25 \%$ in ventricular extrasystole, and $2-5 \%$ in ventricular tachycardia [50]. In contrast, Flemons et al. [51] determined the prevalence of arrhythmias by monitoring patients with and without sleep apnea daily, and found the following disturbances in these 2 groups, respectively: ventricular ectopia (including ventricular tachycardia), 1.3 versus $4.1 \%$; frequent ventricular extrasystole $(>30 / \mathrm{h}), 2.6$ versus $6.2 \%$; atrioventricular blockade of the second degree, 1.3 versus $4.1 \%$; and sinus arrest, 5.2 versus $1.0 \%$. Differences were statistically nonsignificant, and the presence or absence of arrhythmias did not seem to be relevant to the degree of sleep apnea.

To study such conflicting data, Becker et al. [52] conducted Holter monitoring of 239 patients with respiratory disturbances during sleep. The researchers reported an exceptional chronological accuracy between the details of bradyarrhythmias and episodes of respiratory arrest in a dream. The tendency to more frequent disturbances of the rhythm during sleep is confirmed by other observations [53]. Important data for long-term ECG recording were presented by Simantirakis et al. [54]. This was a study of individuals without established cardiovascular disease, pulmonary disease, or diabetes, who underwent a preliminary examination that included tests involving physical activity, invasive electrophysiological examination, echocardiography, and evaluation of the function of external respiration. ECG loop recorders were installed in selected subjects. Based on the results of a 2-month recording, ECG detected significant rhythm disturbances in $48 \%$ of the observations. The researchers noted limitations in the method of 24-h Holter monitoring for the detection of bradyarrhythmias at night.

It is interesting that the tendency to arrhythmias in OSA patients persisted even against the background of treatment. Thus, in individuals with an implanted cardio-

Clues to the Pathophysiology of SCD in OSA verter defibrillator, the incidence of events in severe OSA was 4.7 times that of patients with normal breathing during sleep [55], and recurrent ventricular arrhythmias after radiofrequency ablation were significantly more frequent among patients with OSA [53].

\section{Intrathoracic Pressure}

An additional prorhythmogenic effect appears to be an increase in intrathoracic pressure. Forcing the respiratory effort against the background of apnea creates negative pressure, stimulating cardiac mechanoreceptors and increasing cardiac transmural pressure, thereby leading to dramatic changes in the heart geometry. This can predispose to arrhythmias through the mechanisms of electrical feedback [56]. Ventricular ectopia is most often associated with an increase in the tone of the sympathetic nervous system. Against the background of a decrease in the reserve of repolarization and electrical remodeling of the myocardium, premature impulses can lead to the development of life-threatening tachycardias. Bradyarrhythmia, in contrast, is associated with an increase in the tone of the vagus nerve as a result of episodes of apnea. Parasympathicotonia can lead to atrioventricular blockade and asystole, even in the absence of structural heart disease [57].

\section{Conclusion}

Despite the fact that most respiratory disturbances take place at night, there are few data on the circadian variation of OSA leading to SCD. As mentioned above, studies examining the day-to-night correlation of myocardial instability markers, cardiac arrhythmias, provide contradictory information $[25,27,42,51,54]$. This is undoubtedly of clinical interest but does not allow us to draw strong conclusions about the circadian influence on SCD. In fact, we could not find studies on sleep apnea with convincing evidence of SCD as the end point.

The use of intermediate end points is another problem in the treatment of OSA. Studies which have examined the efficacy of CPAP in patients with cardiac arrhythmia and OSA, evaluated markers such as QT elongation, Tp-e intervals, atrial fibrillation progression, ventricular arrhythmia rate, atrioventricular block grade, and sinus arrest $[25,26,58-60]$. However, these findings are not sufficient to recommend the obligatory implementation of CPAP treatment in order to prevent SCD. In fact, no relevant research on the influence of CPAP or any other treatment on the "hard" end point SCD was found. 
Thus, the abovementioned data emphasize the relationship between OSA and rhythm and conduction disorders and provide some insight into the biochemical and pathophysiological mechanisms potentially participating in this association. The accumulated evidence supports the search for OSA in the differential diagnostic algorithm of arrhythmias, and the presence of sleep apnea and the reduction of oxygen saturation can be regarded as a risk factor for SCD in people with breathing disorders in sleep. It is important to include OSA in the risk list of the Russian National Society of Arrhythmology. Further studies on the treatment of OSA to prevent SCD are needed.

\section{Disclosure Statement}

There were no conflicts of interest.

\section{References}

1 Priori SG, Blomström-Lundqvist C, Mazzanti A, Bloma N, Borggrefe M, Camm J, et al: 2015 ESC Guidelines for the management of patients with ventricular arrhythmias and the prevention of sudden cardiac death. Eur Heart J 2015;36:2793-2867.

2 Chahal AA, Somers VK: Ion channel remodeling - a potential mechanism linking sleep apnea and sudden cardiac death. J Am Heart Assoc 2016;5:1-5.

3 Chugh SS, Reinier K, Teodorescu C, Evanado A, Kehr E, Al Samara M, et al: Epidemiology of sudden cardiac death: clinical and research implications. Progr Cardiovasc Dis 2008; 51 : 213-228.

4 Mansukhani MP, Wang S, Somers VK: Sleep, death, and the heart. Am J Physiol Heart Circ Physiol 2015;309:739-749.

5 Myerburg RJ, Kessler KM, Castellanos A: Sudden cardiac death: structure, function, and time-dependence of risk. Circulation 1992;85:2-10.

6 Spooner PM, Albert C, Benjamin E: Sudden cardiac death, genes, and arrhythmogenesis: consideration of new population and mechanistic approaches from a National Heart, Lung, and Blood Institute workshop, part I. Circulation 2001;103:2361-2364.

7 Spooner PM, Albert C, Benjamin EJ, et al: Sudden cardiac death, genes, and arrhythmogenesis: consideration of new population and mechanistic approaches from a National Heart, Lung, and Blood Institute workshop, part II. Circulation 2001;103:2447-2452.

8 Gami AS, Somers VK (eds): Sudden death and obstructive sleep apnea; in Electrical Diseases of the Heart: Genetics, Mechanisms, Treatment, Prevention. London, Springer, 2007.

9 All-Russian National Society of Arrythmologists: Cliniccheskie recommentasii po electrophisiologicheskim issledovaniyam, cateternoj ablatsii I ispolsovaniyu implantiruyemykh antiaritmicheskih ustrojstv. Moscow, Novaya Redactsia, 2013.

10 Young T, Finn L, Peppard PE: Sleep disordered breathing and mortality: eighteen-year follow-up of the Wisconsin sleep cohort. Sleep 2008;31:1071-1078.
11 Marshall NS, Wong KH, Cullen SR, Knuiman MW, Grunstein RR: Sleep apnea and 20-year follow-up for all-cause mortality, stroke, and cancer incidence and mortality in the Busselton Health Study cohort. J Clin Sleep Med 2014;4:355-362.

12 Gami AS, Olson J, Shen WK, Wright S, Wright RS, Ballman KV, et al: Obstructive sleep apnea and the risk of sudden cardiac death. J Am Coll Cardiol 2013;62:610-615.

13 Ramar K, Dort LC, Katz SG, Lettieri CJ, Harrod CG, Thomas SM, Chervin RD: Clinical practice guideline for the treatment of obstructive sleep apnea and snoring with oral appliance therapy: an update for 2015. J Clin Sleep Med 2015;7:773-827.

14 Lindberg E: Epidemiology of sleep-related obstructive breathing. Sleep Med Rev 2000;4: 411-433.

15 Young T, Palta M, Dempsey J, et al: The occurrence of sleep-disordered breathing among middle-aged adults. N Engl J Med 1993;328:1230-1235.

16 Ancoli-Israel S, Kripke DF, Klauber MR, Mason WJ, Fell R, Kaplan O: Sleep-disordered breathing in community-dwelling elderly. Sleep 1991;14:486-495.

17 Gami AS, Somers VK (eds): Sleep apnea and cardiovascular disease; in Braunwald's Heart Disease: A Textbook of Cardiovascular Medicine, ed 8. Philadelphia, Elsevier Science, 2007.

18 Marshall NS, Wong KK, Liu PY, Cullen SR, Knuiman MW, Grunstein RR: Sleep apnea as an independent risk factor for all-cause mortality: the Busselton Health Study. Sleep 2008; 31:1079-1085.

19 Chan A, Antonio N: Mechanism of sudden cardiac death in obstructive sleep apnea. Sleep Med 2013;14(suppl 1):e95.

20 Zilber AP (ed): Clinicheskaya fisiologiya v anestesiologii I reanimatologii. Moscow, Medicine, 1984.

21 Severin ES (ed): Biochemistry. Moscow, GEOTAR-MED, 2004.

22 Jiang N, Zhou A, Prasad B, Zhou L, Doumit J, Shi G, et al: Obstructive sleep apnea and circulating potassium channel levels. J Am Heart Assoc 2016;5:e003666.
23 Natsionalnye Rossijskie recomendatsii po primineniyu metodiki holterovskogo monitorirovaniya $\mathrm{v}$ klinicheskoj praktike. Ross Cardiol Zh 2014;2:6-71.

24 Latshang TD, Kaufmann B, NussbaumerOchsner Y, Ulrich S, Furian M, Kohler M, et al: Patients with obstructive sleep apnea have cardiac repolarization disturbances when travelling to altitude: randomized, placebocontrolled trial of acetazolamide. Sleep 2016; 9:1632-1637.

25 Shamsuzzaman A, Amin RS, van der Walt C, et al: Daytime cardiac repolarization in patients with obstructive sleep apnea. Sleep Breath 2015;19:1135-1140.

26 Kilicaslan F, Tokatli A, Ozdag F, Uzun M, Uz $\mathrm{O}$, Isilak Z, et al: Tp-e interval, Tp-e/QT ratio, and $\mathrm{Tp}-\mathrm{e} / \mathrm{QTc}$ ratio are prolonged in patients with moderate and severe obstructive sleep apnea. Pacing Clin Electrophysiol 2012;35: 966-972.

27 Borodin NV, Lyshova OV: Electrocardigraficheskie pokasateli electricheskoj nestabilnosti myocarda u bolnykh sindromom obstructivnogo apnoe-gipopnoe vo vremya sna I vpervyje vyjavlennoj aretrialnoj gipertensijej. Arterial Gipertens 2015;3:301-308.

28 Rossi VA, Stoewhas AC, Camen G, Steffel J, Bloch KE, Stradling JR, Kohler M: The effects of continuous positive airway pressure therapy withdrawal on cardiac repolarization: data from a randomized controlled trial. Eur Heart J 2012;17:2206-2212.

29 Roche F, Reynaud C, Pichot V, Duverney B, Costes A, Garet M, et al: Effect of acute hypoxia on QT rate dependence and corrected QT interval in healthy subjects. Am J Cardiol 2003;7:916-919.

30 Baumert M, Smith J, Catcheside P, et al: Variability of QT interval duration in obstructive sleep apnea: an indicator of disease severity. Sleep 2008;31:959-966.

31 Nemati S, Malhotra A, Clifford GD: T-wave alternans patterns during sleep in healthy, cardiac disease and sleep apnea patients. J Electrocardiol 2011;2:126-130. 
32 Sanner B, Konnermann M, Hörstensmeyer D, Burmann-Urbanek M: Clinical significance of ventricular late potentials in patients with obstructive sleep apnoea. J Sleep Res 1995;4: 190-193.

33 Sanner B, Konnermann M, Hörstensmeyer D, Burmann-Urbanek M: Prevalence of ventricular late potentials in patients with obstructive sleep apnea syndrome. Clin Cardiol 1999 3:219-224.

34 Foster GE, Poulin MJ, Hanly PJ: Intermittent hypoxia and vascular function: implications for obstructive sleep apnoea. Exp Physiol 2007;92:51-65.

35 Guilleminault C, Connoly S, Winkle R, Tilkian A: Cyclical variation of the heart rate in sleep apnea syndrome. Lancet 1984;21:126131.

36 Le Heuzey JY, Romejko P, Fleury B, et al: Holter monitoring in the diagnosis of sleep apnea syndrome. J Am Col Cardiol 1989;13: 189A.

37 Shiomi T, Guilleminault C, Sasanabe R, Hirota I, Maekawa M, Kobayashi T: Augmented very low frequency component of heart rate variability during obstructive sleep apnea. Sleep 1996;19:370-377.

38 Galal I: Nocturnal heart rate variability analysis as a screening tool for obstructive sleep apnea syndrome. Egypt J Chest Dis Tuberc 2012;3:181-195.

39 Zhu K, Chemla D, Roisman G, Mao W, Bazizi S, Lefevre A, Escourrou P: Overnight heart rate variability in patients with obstructive sleep apnoea: a time and frequency domain study. Clin Exp Pharmacol Physiol 2012;11: 901-908.

40 Montemurro TL, Floras JS, Picton P, Kasai T, Alshaer H, Gabriel JM, Bradley TD: Relationship of heart rate variability to sleepiness in patients with obstructive sleep apnea with and without heart failure. J Clin Sleep Med 2014; 3:271-276.

41 Somers VK, Dyken ME, Clary MP, Abboud FM: Sympathetic neural mechanisms in obstructive sleep apnea. J Clin Invest 1995;96: 1897-1904.
42 Narkiewicz K, Montano N, Cogliati C, van de Borne PJ, Dyken ME, Somers VK: Altered cardiovascular variability in obstructive sleep apnea. Circulation 1998;98:1071-1077.

43 Kufoy E, Palma J-A, Lopez J, Alegre M, Urrestarazu E, Artieda J, Iriarte J: Changes in the heart rate variability in patients with obstructive sleep apnea and its response to acute CPAP treatment. PLoS One 2012;7:e33769.

44 Narkiewicz K, van de Borne PJ, Montano N, Dyken ME, Phillips BG, Somers VK: Contribution of tonic chemoreflex activation to sympathetic activity and blood pressure in patients with obstructive sleep apnea. Circulation 1998;97:943-945.

45 Arnaud C, Morand J, Pepin JL, Godin-Ribuot D: Obstructive sleep apnea and the risk of sudden cardiac death: chronic intermittent hypoxia promotes myocardial ischemia-related ventricular arrhythmias and infarction. Building the evidence. Cardiovasc Syst Outcomes Sleep Disord 2015;1:6105.

46 Koehler U, Schafer H: Is obstructive sleep apnea (OSA) a risk factor for myocardial infarction and cardiac arrhythmias in patients with coronary heart disease (CHD)? Sleep 1996;19: 283-286.

47 Liston R, Deegan PC, Mc Creery C, McNicholas WT: Role of respiratory sleep disorders in the pathogenesis of nocturnal angina and arrhythmias. Postgrad Med J 1994;70:275-280.

48 Shepard JW: Hypertension, cardiac arrhythmias, myocardial infarction, and stroke in relation to obstructive sleep apnea. Clin Chest Med 1992;13:437-458.

49 Fichter J, Bauer D, Arampatzis S, Fries R, Heisel A, Sybrecht GW: Sleep-related breathing disorders are associated with ventricular arrhythmias in patients with an implantable cardioverter-defibrillator. Chest 2002;2:568-561.

50 Hersi AS: Obstructive sleep apnea and cardiac arrhythmias. Ann Thorac Med 2010;1:10-17.

51 Flemons WW, Remmers JE, Gillis AM: Sleep apnea and cardiac arrhythmias: is there a relationship? Am Rev Respir Dis 1993;148:618621.

52 Becker $\mathrm{H}$, Brandenburg U, Peter $\mathrm{JH}$, von Wichert P: Reversal of sinus arrest and atrioventricular conduction block in patients with sleep apnea during nasal continuous positive airway pressure. Am J Respir Crit Care Med 1995;151:215-218.
53 Koshino Y, Satoh M, Katayose M, Kuroki K, Sekiguchi Y, Yamasaki H, et al: Sleep apnea and ventricular arrhythmias: clinical outcome, electrophysiologic characteristics, and follow-up after catheter ablation. J Cardiol 2010;12:211-216

54 Simantirakis EN, Schiza SI, Marketou E, Chrysostomakis SI, Chlouverakis GI, Klapsinos NC: Severe bradyarrhythmias in patients with sleep apnoea: the effect of continuous positive airway pressure treatment. A longterm evaluation using an insertable loop recorder. Eur Heart J 2004;25:1070-1076.

55 Clay R, Kapur VK, Gronquist JM, Tereshenko LG, Khan A: Risk of obstructive sleep apnea in patients with pacemakers and implantable cardioverter defibrillators and incidence of ventricular arrhythmia. Am J Respir Crit Care Med 2016;193:A4206.

56 Franz MR: Mechano-electrical feedback in ventricular myocardium. Cardiovasc Res 1996;32:15-24.

57 Guilleminault C, Connolly SJ, Winkle RA: Cardiac arrhythmia and conduction disturbances during sleep in 400 patients with sleep apnea syndrome. Am J Cardiol 1983;52:490494.

58 Holmqvist F, Guan N, Zhu Z, et al: Impact of obstructive sleep apnea and continuous positive airway pressure therapy on outcomes in patients with atrial fibrillation - results from the Outcomes Registry for Better Informed Treatment of Atrial Fibrillation (ORBIT-AF). Am Heart J 2015;169:647-654.e2.

59 Abe H, Takahashi M, Yaegashi H, Eda S, Tsunemoto H, Kamikozawa M, et al: Efficacy of continuous positive airway pressure on arrhythmias in obstructive sleep apnea patients. Heart Vessels 2010;25:63-69.

60 Wu X, Liu Z, Chang SC, Fu C, Li W, Jiang H, Jiang L, Li S: Screening and managing obstructive sleep apnoea in nocturnal heart block patients: an observational study. Respir Res 2016;17:16. 